\title{
Non-covalent interactions at electrochemical interfaces: one model fits all?
}

Cite this: Phys. Chem. Chem. Phys., 2014, 16, 14281

Received 7th August 2013, Accepted 29th May 2014

DOI: $10.1039 / c 3 c p 53354 a$

www.rsc.org/pccp

\author{
Gema Cabello, ${ }^{a}$ Ezequiel P. M. Leiva, ${ }^{b}$ Claudio Gutiérrez ${ }^{a}$ and Angel Cuesta*ac
}

\section{Introduction}

Traditionally, the influence of cations on the properties of, and on the processes occurring at, the electrical double layer has received little attention. Although the adsorption of alkali-metal cations on polycrystalline Pt electrodes was already reported in the early 1970 's, ${ }^{1,2}$ and although Feliu and co-workers studied in the last few decades the effect of alkali-metal cations on sulfate $^{3,4}$ and phosphate ${ }^{5}$ adsorbed on Pt(111) electrodes, the report by Strmenik et al. ${ }^{6}$ in 2009 of a remarkable cation effect on the electrocatalytic activity of $\mathrm{Pt}(111)$ towards the oxygen reduction reaction (ORR), the hydrogen oxidation reaction (HOR), and the methanol oxidation reaction (MOR) in alkaline solutions has provoked a surge of articles on this subject. ${ }^{7-15}$ In all these new contributions, and following Strmcnik et al., ${ }^{6}$ the effect of the cation has been attributed to non-covalent interactions at the electrical double layer (essentially, electrostatic interactions between specifically adsorbed anions and the cations, leading to the formation of surface-anchored cation-anion, or cation-dipole pairs). However, with only two exceptions, ${ }^{7,9}$ all these studies simply reported a qualitative description of the effect, without a quantitative and systematic study that could lead to a deeper understanding of the physical and chemical phenomena behind it.

Recently, ${ }^{9}$ we have shown that the effect of alkali-metal cations $\left(\mathrm{M}^{+}\right)$on the cyclic voltammogram of cyanide-modified $\mathrm{Pt}(111)$ electrodes in sulfuric or perchloric acid solutions can be

\footnotetext{
a Instituto de Química Física “Rocasolano”, CSIC, C. Serrano 119, E-28006, Madrid, Spain

${ }^{b}$ Facultad de Ciencias Químicas, Universidad Nacional de Córdoba, INFIQC, Córdoba, Argentina

${ }^{c}$ Department of Chemistry, School of Natural and Computing Sciences, University of Aberdeen, Aberdeen AB24 3UE,UK.E-mail: angel.cuestaciscar@abdn.ac.uk
}

quantitatively described by a simple model, which essentially rests on the competition between $\mathrm{H}^{+}$and $\mathrm{M}^{+}$for the same adsorption sites, namely, the $\mathrm{N}$ atom of the $\mathrm{CN}$ groups anchored to the surface through the $\mathrm{C}$ atom. We report here a systematic study of the effect of the alkali-metal cations on two voltammetric features of $\operatorname{Pt}(111)$ in sulfuric acid solutions associated with (bi)sulfate adsorption. Our results suggest that our previously developed model is of general applicability to non-covalent interactions at the electrical double layer.

\section{Experimental section}

The working electrode was a bead-type Pt single crystal (ca. $2 \mathrm{~mm}$ in diameter) prepared according to the method developed by Clavilier et al., ${ }^{16}$ oriented and polished parallel to the (111) plane. Before each experiment, the crystal was annealed in the flame of a Bunsen burner and cooled in a $\mathrm{H}_{2}-\mathrm{N}_{2}$ atmosphere. Once the crystal was sufficiently cold ( $c a .20$ seconds after having been introduced in the flask containing the $\mathrm{H}_{2}-\mathrm{N}_{2}$ mixture) the $\mathrm{H}_{2}$ flux was stopped, and $\mathrm{CO}$ was flown into the flask, in which the electrode was left for 5 additional minutes, during which a saturated $\mathrm{CO}$ adlayer was formed. The COprotected electrode was then transferred to the electrochemical cell, where the $\mathrm{CO}$ adlayer was oxidatively stripped from the electrode surface, a clean and well-ordered $\operatorname{Pt}(111)$ surface being thus exposed to the electrolyte.

A two-compartment, three-electrode Pyrex-glass cell was used for the electrochemical measurements. The electrolytes were prepared using ultrapure Milli-Q water ( $18 \mathrm{M} \Omega \mathrm{cm}, 3 \mathrm{ppb}$ TOC), concentrated $\mathrm{H}_{2} \mathrm{SO}_{4}$ (Merck suprapur), concentrated $\mathrm{HClO}_{4}$ (Merck, p.a.), and $\mathrm{M}_{2} \mathrm{SO}_{4}$, with $\mathrm{M}=\mathrm{Li}$ (Aldrich, $\geq 99.99 \%$ ), $\mathrm{Na}$ (Aldrich, 99.99\%), K (Merck, Suprapur, 99.999\%) or Cs (Aldrich, 99.99\%). Nitrogen (N50) was used to deoxygenate the solutions, 
hydrogen (N50) and nitrogen (N50) were used to make the $\mathrm{H}_{2}-\mathrm{N}_{2}$ atmosphere in which the single-crystal electrodes were cooled after annealing, and carbon monoxide (N47, aluminium alloy cylinders) was used to form the protective $\mathrm{CO}$ adlayer. All gases were supplied by Air Liquide. A reversible hydrogen electrode (RHE) was used as reference, and the auxiliary electrode was a Pt wire.

\section{Results and discussion}

The two voltammetric features mentioned in the introduction, namely, a spike and a hump, can be seen in Fig. 1, which shows cyclic voltammograms (CVs) of Pt(111) in 0.05, 0.1, 0.5 and $1 \mathrm{M}$ sulfuric acid. The adsorption of (bi)sulfate starts just after hydrogen desorption, giving rise to a broad feature preceding the spike that appears between ca. $0.4\left(1 \mathrm{M} \mathrm{H}_{2} \mathrm{SO}_{4}\right)$ and $c a .0 .5 \mathrm{~V}$ (0.05 $\mathrm{M} \mathrm{H}_{2} \mathrm{SO}_{4}$ ) and signals the formation of an ordered $(\sqrt{3} \times \sqrt{7}) R 19.1^{\circ}$ structure with a (bi)sulfate coverage of $0.20 .^{17}$ The same disorder/order phase transition, leading to the same structure, occurs on the (111) faces of $\mathrm{Au},{ }^{18,19} \mathrm{Rh}^{20} \mathrm{Ir}^{21} \mathrm{Pd}^{22,23}$ and $\mathrm{Cu}^{24}$ In all the cases, the observation in STM images of a secondary tunneling maximum led to suggest a hydration of this structure, an assumption that has received confirmation from radioactive labeling experiments. ${ }^{25}$ This hydrogen bond network would stabilize the ordered structure. However, whether the adlayer is composed of sulfate or bisulfate (hence the usually employed ambivalent term (bi)sulfate), and whether the coadsorbate is $\mathrm{H}_{3} \mathrm{O}^{+}$ or $\mathrm{H}_{2} \mathrm{O}$, has been the subject of considerable debate. $7,17,18,20,25-36$ The (uncorrected for double layer charging) charge of $c a .96 \mu \mathrm{C} \mathrm{cm}^{-2}$ determined from the cyclic voltammograms, together with the 0.20 ML coverage determined from the STM images, imply that two electrons are transferred per adsorbate, i.e., they suggest that, from a purely stoichiometric point of view the adsorption process is $\mathrm{SO}_{4}{ }^{2-} \rightleftharpoons \mathrm{SO}_{4}(\mathrm{ad})+2 \mathrm{e}$ (or $\mathrm{SO}_{4}{ }^{2-}+\mathrm{H}^{+} \rightleftharpoons$ $\mathrm{SO}_{4}-\mathrm{H}^{+}(\mathrm{ad})+2 \mathrm{e}$ if $\mathrm{H}_{3} \mathrm{O}^{+}$is the coadsorbate that stabilizes the $(\sqrt{3} \times \sqrt{7}) R 19.1^{\circ}$ structure).

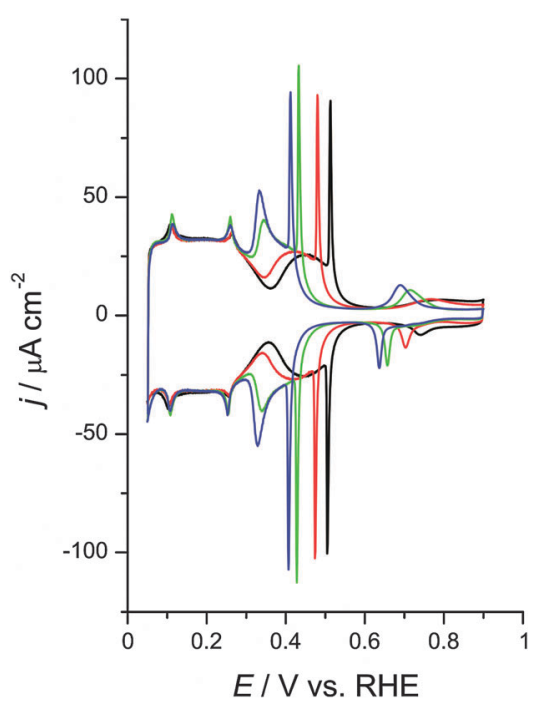

Fig. 1 Cyclic voltammograms, at $50 \mathrm{mV} \mathrm{s}^{-1}$, of $\mathrm{Pt}(111)$ in 0.05 (black), 0.1 (red), 0.5 (green), and $1 \mathrm{M}$ (blue) $\mathrm{H}_{2} \mathrm{SO}_{4}$.
The $(\sqrt{3} \times \sqrt{7}) R 19.1^{\circ}$ structure disappears in the potential region of the hump, about $0.75 \mathrm{~V}$ in $0.1 \mathrm{M} \mathrm{H}_{2} \mathrm{SO}_{4}$, what led Funtikov et al. to propose that the hump corresponds to the onset of $\mathrm{OH}$ adsorption. ${ }^{17}$ Adsorption of $\mathrm{OH}$ within the (bi)sulfate adlayer was also invoked by Markovic et al., ${ }^{37}$ and later by Saravanan et al., ${ }^{38}$ as the origin of the hump, but this runs contrary to its experimentally observed $\mathrm{pH}$ dependence. ${ }^{3}$ Shingaya and Ito $^{39}$ suggested that this feature corresponds to the conversion, with increasing potential, of adsorbed bisulfate to adsorbed sulfuric acid $\left(\mathrm{HSO}_{4}(\mathrm{ad})+\mathrm{H}^{+}+\mathrm{e} \rightleftharpoons \mathrm{H}_{2} \mathrm{SO}_{4}(\mathrm{ad})\right)$, a suggestion that must be discarded because this process is a reduction, and, furthermore, should have a $\mathrm{pH}$ dependence contrary to that observed by García et al. ${ }^{3}$ The increase of the hump potential with increasing $\mathrm{pH}$ at $\mathrm{pH}$ between 2.5 and 3.5 observed by García et al. ${ }^{3}$ unambiguously shows that, in this $\mathrm{pH}$ region, this voltammetric feature does not involve $\mathrm{OH}$ adsorption. The only electroadsorption process that can be involved in both the spike and the hump is that of (bi)sulfate. However, as noted by García et al., ${ }^{3}$ the decrease, with a slope of $60 \mathrm{mV}$, of the hump potential with increasing $\mathrm{pH}$ at $\mathrm{pH}>3.5$, must be due to a change of the adsorbing species, namely, to the co-adsorption of $\mathrm{OH}$ within the (bi)sulfate adlayer at $\mathrm{pH}>3.5$.

The charge density associated with the hump, about $25 \mu \mathrm{C} \mathrm{cm}^{-2}$, and $c a .12 \mu \mathrm{C} \mathrm{cm}^{-2}$ after double-layer correction, is independent of the $\mathrm{H}_{2} \mathrm{SO}_{4}$ concentration, and corresponds to the adsorption of 0.025 additional monolayers of sulfate, which provokes the disruption of the $(\sqrt{3} \times \sqrt{7}) R 19.1^{\circ}$ structure, as has been shown by STM. ${ }^{17}$ The charge of the hump coincides with that reported by García et $a .^{3}$ The fact that the potential has to be increased by $c a .0 .25 \mathrm{~V}$ before the sulfate coverage can be increased beyond the $0.20 \mathrm{ML}$ coverage reached in the spike, must be due to the stability conferred to this ordered adlayer by the hydrogen bond network.

We studied the effect of the alkali-metal cations on the spike and the hump. Obviously, the cation concentration cannot be varied without simultaneously altering the total anion concentration and/ or the $\mathrm{pH}$. The easiest way to increase the cation concentration without altering the $\mathrm{pH}$ and the total sulfate $\left(\mathrm{SO}_{4}{ }^{2-}+\mathrm{HSO}_{4}{ }^{-}\right)$ concentration would be to use different concentrations of alkalimetal perchlorates. We used, however, sulfates instead of perchlorates because, typically, the former contain less impurities, high purity being a must when working under ultra-clean conditions. We prepared $(0.1-x) \mathrm{M} \mathrm{H}_{2} \mathrm{SO}_{4}+x \mathrm{M} \mathrm{M}_{2} \mathrm{SO}_{4}+2 x \mathrm{M} \mathrm{HClO}_{4}$ solutions, whose composition is identical to $0.1 \mathrm{M} \mathrm{H}_{2} \mathrm{SO}_{4}+2 x \mathrm{M} \mathrm{MClO}_{4}$ solutions, this notation being used in the following. Since perchlorate specific adsorption is negligible, its only effect will be to increase the ionic strength of the solution, but this effect will be the same for all the alkali-metal cations.

Fig. 2 shows the CVs of $\mathrm{Pt}(111)$ in $0.1 \mathrm{M} \mathrm{H}_{2} \mathrm{SO}_{4}$ containing different concentrations of $\mathrm{Li}^{+}$(Fig. 2a), $\mathrm{Na}^{+}$(Fig. 2b), $\mathrm{K}^{+}$(Fig. 2c) and $\mathrm{Cs}^{+}$(Fig. 2d). Only the CVs at cation concentrations of $10^{-4}$, $10^{-3}, 10^{-2}$ and $5 \times 10^{-2} \mathrm{M}$ are shown for the sake of clarity. Fig. 3 illustrates the effect of increasing concentrations of $\mathrm{Li}^{+}$(black), $\mathrm{Na}^{+}$ (red), $\mathrm{K}^{+}$(green) and $\mathrm{Cs}^{+}$(blue) on the spike potential (squares) and on the hump potential (circles) in the CVs of $\mathrm{Pt}(111)$ in $0.1 \mathrm{M} \mathrm{H}_{2} \mathrm{SO}_{4}$. 

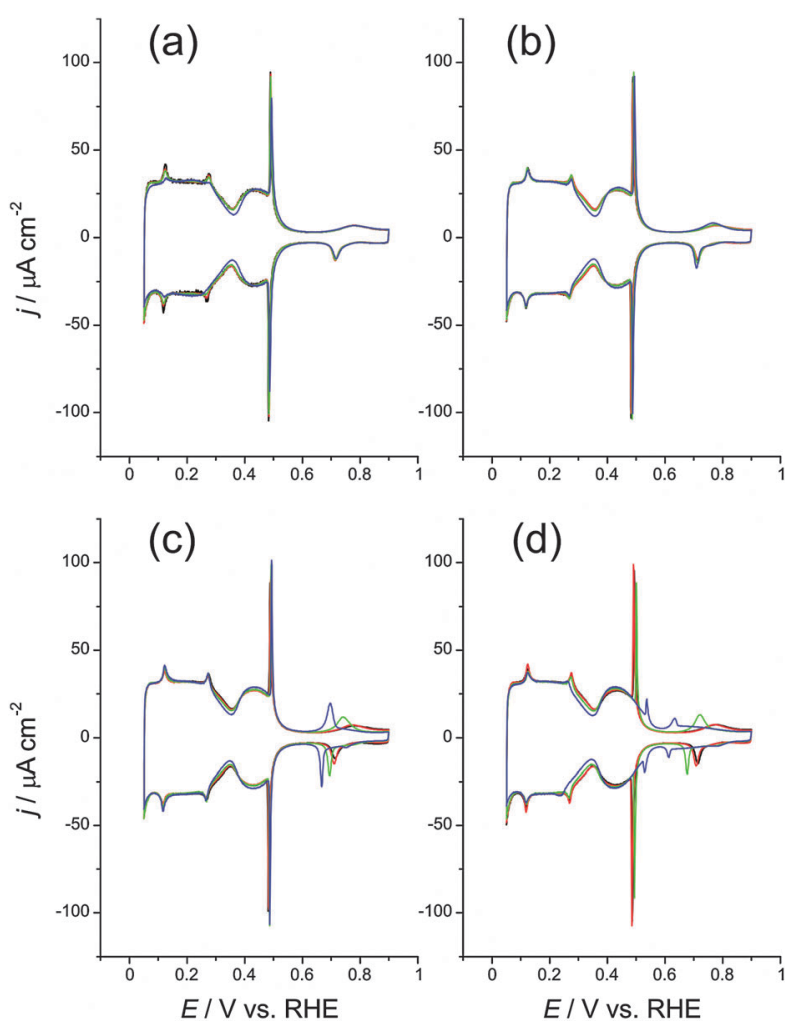

Fig. 2 Cyclic voltammograms, at $50 \mathrm{mV} \mathrm{s}^{-1}$, of $\mathrm{Pt}(111)$ in $0.1 \mathrm{M} \mathrm{H}_{2} \mathrm{SO}_{4}+$ $x \mathrm{MMClO}_{4} \cdot \mathrm{M}=\mathrm{Li}^{+}$(a), $\mathrm{Na}^{+}$(b), $\mathrm{K}^{+}$(c) or $\mathrm{Cs}^{+}$(d). $x=10^{-4}$ (black), $10^{-3}$ (red), $10^{-2}$ (green) and $5 \times 10^{-2}$ (blue).

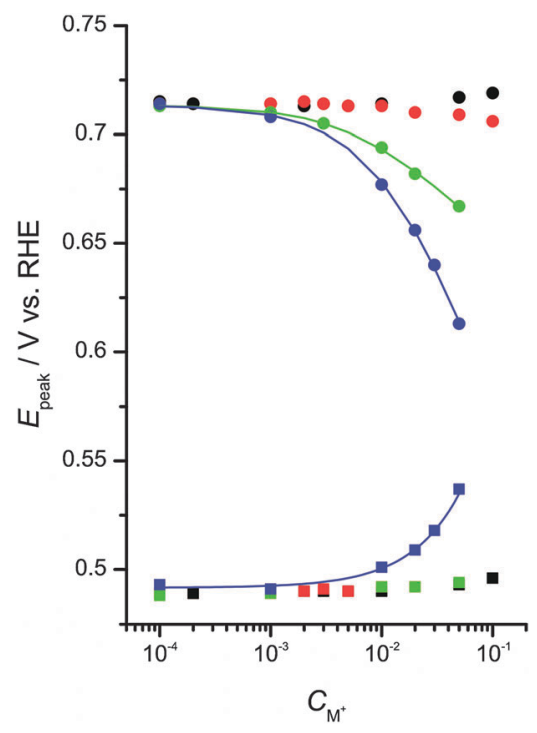

Fig. 3 Semilogarithmic plots of the dependence of the spike potential in the positive sweep (squares), and of the hump potential in the negative sweep (circles) in the $\mathrm{CV}$ at $50 \mathrm{mV} \mathrm{s}^{-1}$ of $\mathrm{Pt}(111)$ in $0.1 \mathrm{M} \mathrm{H}_{2} \mathrm{SO}_{4}$ on the concentration of alkali-metal cations (black: $\mathrm{Li}^{+}$; red: $\mathrm{Na}^{+}$; green: $\mathrm{K}^{+}$; blue: $\left.\mathrm{Cs}^{+}\right)$. The lines are fits of the experimental data for the spike and the hump to eqn (7) and (8), respectively.

Even at the highest concentration used, the potential of the spike is but very slightly increased in all cases but $\mathrm{Cs}^{+}$, this cation additionally decreasing the intensity of the spike (Fig. 2d).
The hump becomes sharper and more reversible, and its potential becomes more negative, at high concentrations of $\mathrm{K}^{+}$and $\mathrm{Cs}^{+}$(a similar effect was observed by García et al. ${ }^{3}$ and Garcia-Araez et al. ${ }^{7}$ in the case of $\mathrm{Na}^{+}$at $c_{\mathrm{Na}^{+}} \geq 0.2 \mathrm{M}$ ). The magnitude of these effects increases in the order $\mathrm{Li}^{+}<\mathrm{Na}^{+}<$ $\mathrm{K}^{+}<\mathrm{Cs}^{+}$. All these results are in good agreement with previous reports. ${ }^{3,4,7}$

As shown in Fig. 3, the effect of $\mathrm{Cs}^{+}$on the spike is similar to that found previously for a hydrogen adsorption feature on cyanide-modified $\mathrm{Pt}(111)$ electrodes. ${ }^{9}$ Since the spike is due to a phase transition within the sulfate adlayer, and must therefore appear at the same, critical local coverage of $\left(\mathrm{H}^{+}-\mathrm{SO}_{4}\right)_{\mathrm{ad}}$, its positive potential shift with increasing $\mathrm{Cs}^{+}$concentration can be attributed to the substitution of $\mathrm{H}^{+}$by $\mathrm{Cs}^{+}$. We can describe the adsorption equilibrium of $\left(\mathrm{M}^{+}-\mathrm{SO}_{4}\right)_{\mathrm{ad}}$ as $\mathrm{M}^{+}+\mathrm{SO}_{4}{ }^{2-} \rightleftharpoons$ $\mathrm{M}^{+}-\mathrm{SO}_{4}(\mathrm{ad})+2 \mathrm{e}$. Assuming that both this adsorption and that of the $\left(\mathrm{H}^{+}-\mathrm{SO}_{4}\right)_{\mathrm{ad}}$ pair can be described by the Langmuir isotherm, which is a good approximation at least at the lower $\mathrm{H}_{2} \mathrm{SO}_{4}$ concentrations, that $a_{\mathrm{SO}_{4}{ }^{2-}}=c_{\mathrm{SO}_{4^{2-}}}$, that $a_{\mathrm{H}^{+}}=c_{\mathrm{H}^{+}}$, and that $a_{\mathrm{M}^{+}}=c_{\mathrm{M}^{+}}$, we can write:

$$
\begin{aligned}
a_{\left(\mathrm{H}^{+}-\mathrm{SO}_{4}\right)_{\mathrm{ad}}}^{\text {spike }} & =\frac{\theta_{\mathrm{H}^{+}-\mathrm{SO}_{4}}^{\text {spie }}}{1-\theta_{\mathrm{H}^{+}-\mathrm{SO}_{4}}^{\text {sie }}-\theta_{\mathrm{M}^{+}-\mathrm{SO}_{4}}^{\text {spiee }}} \\
& =K_{\mathrm{L}}^{\mathrm{H}^{+}-\mathrm{SO}_{4}{ }_{\mathrm{H}^{+}} c_{\mathrm{SO}_{4}{ }^{2-}} \exp \left(\frac{n F \Delta \phi}{R T}\right)} \\
a_{\left(\mathrm{M}^{+}-\mathrm{SO}_{4}\right)_{\mathrm{ad}}}^{\text {spike }} & =\frac{\theta_{\mathrm{M}^{+}-\mathrm{SO}_{4}}^{\text {spike }}}{1-\theta_{\mathrm{H}^{+}-\mathrm{SO}_{4}}^{\text {sie }}-\theta_{\mathrm{M}^{+}-\mathrm{SO}_{4}}^{\text {spike }}} \\
& =K_{\mathrm{L}}^{\mathrm{M}^{+}-\mathrm{SO}_{4}} c_{\mathrm{M}^{+}} c_{\mathrm{SO}_{4}{ }^{2-}} \exp \left(\frac{n F \Delta \phi}{R T}\right)
\end{aligned}
$$

where $a_{\left(\mathrm{H}^{+}-\mathrm{SO}_{4}\right)_{\text {ad }}}^{\text {spie }}$ and $a_{\left(\mathrm{M}^{+}-\mathrm{SO}_{4}\right)_{\text {ad }}}^{\text {spike }}$ are the activity of adsorbed $\left(\mathrm{H}^{+}-\mathrm{SO}_{4}\right)_{\mathrm{ad}}$ and $\left(\mathrm{M}^{+}-\mathrm{SO}_{4}\right)_{\mathrm{ad}}$, respectively, at the spike, $K_{\mathrm{L}}^{\mathrm{H}^{+}-\mathrm{SO}_{4}}$ and $K_{\mathrm{L}}^{\mathrm{M}^{+}-\mathrm{SO}_{4}}$ are the Langmuir constants for the adsorption of the $\left(\mathrm{H}^{+}-\mathrm{SO}_{4}\right)_{\text {ad }}$ and the $\left(\mathrm{M}^{+}-\mathrm{SO}_{4}\right)_{\text {ad }}$ pair, respectively, $\theta_{\mathrm{H}^{+}-\mathrm{SO}_{4}}^{\text {spie }}$ and $\theta_{\mathrm{M}^{+}-\mathrm{SO}_{4}}^{\text {spie }}$ are their corresponding surface coverages at the spike, $n$ is the number of electrons crossing the interface per adsorbed $\left(\mathrm{H}^{+}-\mathrm{SO}_{4}\right)_{\mathrm{ad}}$ or $\left(\mathrm{M}^{+}-\mathrm{SO}_{4}\right)_{\mathrm{ad}}$ pair, $\Delta \phi$ is the potential drop across the electrode-electrolyte interface, $F$ is the Faraday constant, and $R$ and $T$ have their usual meaning. Since $\Delta \phi$ is the same in both cases, we can write:

$$
\begin{aligned}
& \frac{\theta_{\mathrm{H}^{+}-\mathrm{SO}_{4}}^{\text {sipe }}}{1-\theta_{\mathrm{H}^{+}-\mathrm{SO}_{4}}^{\text {spe }}-\theta_{\mathrm{M}^{+}-\mathrm{SO}_{4}}^{\mathrm{spike}_{\mathrm{L}}}} \frac{1}{K^{\mathrm{H}^{+}-\mathrm{SO}_{4}} c_{\mathrm{H}^{+}}} \\
& =\frac{\theta_{\mathrm{M}^{+}-\mathrm{SO}_{4}}^{\text {spike }}}{1-\theta_{\mathrm{H}^{+}-\mathrm{SO}_{4}}^{\mathrm{spie}}-\theta_{\mathrm{M}^{+}-\mathrm{SO}_{4}}^{\mathrm{spike}_{\mathrm{L}}}} \frac{1}{K_{\mathrm{L}}^{\mathrm{M}^{+}-\mathrm{SO}_{4}} c_{\mathrm{M}^{+}}}
\end{aligned}
$$

from which:

$$
\theta_{\mathrm{M}^{+}-\mathrm{SO}_{4}}^{\text {spike }}=\frac{K_{\mathrm{L}}^{\mathrm{M}^{+}-\mathrm{SO}_{4}} \theta_{\mathrm{H}^{+}-\mathrm{SO}_{4}}^{\mathrm{spike}} c_{\mathrm{M}^{+}}}{K_{\mathrm{L}}^{\mathrm{H}^{+}-\mathrm{SO}_{4}} c_{\mathrm{H}^{+}}}
$$


The spike corresponds to the formation of an ordered $\left(\mathrm{H}^{+}-\mathrm{SO}_{4}\right)_{\mathrm{ad}}$ adlayer at a critical coverage, and, since it is reversible, it must obey Nernst's equation:

$$
E_{\text {spike }}=E_{\text {spike }}^{0}+\frac{R T}{n F} \ln \frac{a_{\left(\mathrm{H}^{+}-\mathrm{SO}_{4}\right)_{\mathrm{ad}}}^{\text {spike }}}{a_{\mathrm{H}^{+}} a_{\mathrm{SO}_{4}{ }^{2-}}}
$$

where $a_{\mathrm{H}^{+}}$and $a_{\mathrm{SO}_{4} 4^{-}}$are the activities of protons and sulfate in the solution, respectively, and $E_{\text {spike }}^{0}$ is the standard spike potential, i.e., the spike potential at standard temperature and pressure, $\mathrm{pH} 0$, and unit activity of sulfate in solution and of adsorbed $\left(\mathrm{H}^{+}-\mathrm{SO}_{4}\right)_{\mathrm{ad}}$.

In the presence of adsorbed $\left(\mathrm{M}^{+}-\mathrm{SO}_{4}\right)_{\text {ad }}$ pairs, and assuming Langmuir adsorption for both $\left(\mathrm{H}^{+}-\mathrm{SO}_{4}\right)_{\mathrm{ad}}$ and $\left(\mathrm{M}^{+}-\mathrm{SO}_{4}\right)_{\mathrm{ad}}$, $a_{\left(\mathrm{H}^{+}-\mathrm{SO}_{4}\right)_{\mathrm{ad}}}^{\text {spike }}=\frac{\theta_{\mathrm{H}^{+}-\mathrm{SO}_{4}}^{\text {spike }}}{1-\theta_{\mathrm{H}^{+}-\mathrm{SO}_{4}}^{\text {spike }}-\theta_{\mathrm{M}^{+}-\mathrm{SO}_{4}}^{\text {spie }}}($ eqn (1)). Assuming, in a first approximation, that $\theta_{\mathrm{H}^{+}-\mathrm{SO}_{4}}^{\text {spike }}$ is constant, eqn (5) becomes, for a given $\mathrm{pH}$ and sulfate concentration in solution:

$$
E_{\text {spike }}=E_{\text {spike }}^{\prime}-\frac{R T}{n F} \ln \left(1-\frac{\theta_{\mathrm{M}^{+}-\mathrm{SO}_{4}}^{\text {spie }}}{1-\theta_{\mathrm{H}^{+}-\mathrm{SO}_{4}}^{\text {spike }}}\right)
$$

where $E_{\text {spike }}{ }^{\prime}=E_{\text {spike }}^{0}-\frac{R T}{F} \ln a_{\mathrm{H}^{+}} a_{\mathrm{SO}_{4}^{2-}}+\frac{R T}{F} \ln \frac{\theta_{\mathrm{H}^{+}-\mathrm{SO}_{4}}^{\text {spike }}}{1-\theta_{\mathrm{H}^{+}-\mathrm{SO}_{4}}^{\text {spike }}}$ is the spike potential for a given $\mathrm{pH}$ and sulfate activity in solution in the absence of $\mathbf{M}^{+}$(i.e., for zero coverage of $\left.\left(\mathrm{M}^{+}-\mathrm{SO}_{4}\right)_{\mathrm{ad}}\right)$. Substitution of $\theta_{\mathrm{M}^{+}-\mathrm{SO}_{4}}^{\text {spike }}$ from eqn (4) into (6) yields:

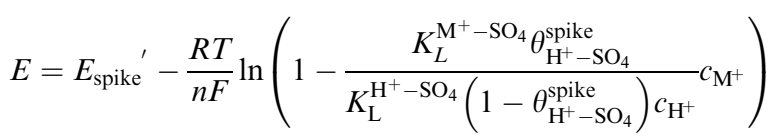

which, if both $\theta_{\mathrm{H}^{+}-\mathrm{SO}_{4}}^{\text {spie }}$ and $c_{\mathrm{H}^{+}}$remain constant, is equivalent to the equation recently derived by us from the model developed to describe the effect of alkali-metal cations on the $\mathrm{CV}$ of cyanide-modified Pt(111) electrodes. ${ }^{9}$ As shown in Fig. 3, with the above assumption eqn (7) describes very well the dependence of the potential of the spike on the concentration of $\mathrm{Cs}^{+}$ for $10^{-4} \mathrm{M}<c_{\mathrm{Cs}^{+}}<5 \times 10^{-2} \mathrm{M}$, albeit with $n=0.2$, a question that will be discussed below. The effect of the other cations on the spike at the concentrations used is too small to attempt a fitting. The fit yields a value of $\frac{K_{\mathrm{L}}^{\mathrm{Cs}^{+}-\mathrm{SO}_{4}} \theta_{\mathrm{H}^{+}-\mathrm{SO}_{4}}^{\text {spike }}}{K_{\mathrm{L}}^{\mathrm{H}^{+}-\mathrm{SO}_{4}}\left(1-\theta_{\mathrm{H}^{+}-\mathrm{SO}_{4}}^{\text {spie }}\right) c_{\mathrm{H}^{+}}}$of ca. $5 \mathrm{M}^{-1}$ (which, taking into account that $\theta_{\mathrm{H}^{+}-\mathrm{SO}_{4}}^{\text {spie }}=0.20$ and $c_{\mathrm{H}^{+}}=$ $0.1 \mathrm{M}$, corresponds to a reasonable value of $c a .2$ for $\left.\frac{K_{\mathrm{L}}^{\mathrm{Cs}^{+}-\mathrm{SO}_{4}}}{K_{\mathrm{L}}^{\mathrm{H}^{+}-\mathrm{SO}_{4}}}\right)$.

The height of the spike in the $\mathrm{CV}$ of $\mathrm{Pt}(111)$ electrodes decreases with decreasing the domain size of the $(\sqrt{3} \times \sqrt{7}) R 19.1^{\circ}$ structure. The very small effect of $\mathrm{Li}^{+}, \mathrm{Na}^{+}$ and $\mathrm{K}^{+}$on both the potential and the charge of the spike suggests that, in this potential region, and at the relatively low concentrations used here (at higher concentrations, $\mathrm{Na}^{+}$and $\mathrm{K}^{+}$ do affect both the position and the height of the spike ${ }^{3,7}$ ),
$\left(\mathrm{Li}^{+}-\mathrm{SO}_{4}\right)_{\mathrm{ad}},\left(\mathrm{Na}^{+}-\mathrm{SO}_{4}\right)_{\mathrm{ad}}$ and $\left(\mathrm{K}^{+}-\mathrm{SO}_{4}\right)_{\mathrm{ad}}$ ion pairs cannot displace $\left(\mathrm{H}^{+}-\mathrm{SO}_{4}\right)_{\text {ad }}$ from the electrode surface (equivalently, $\mathrm{Li}^{+}$, $\mathrm{Na}^{+}$and $\mathrm{K}^{+}$cannot displace $\mathrm{H}^{+}$from the $\left(\mathrm{H}^{+}-\mathrm{SO}_{4}\right)_{\mathrm{ad}}$ network). This is probably due to the extra stability provided to the sulfate adlayer by the hydrogen bond network present in this structure. In contrast, the interaction of $\left(\mathrm{Cs}^{+}-\mathrm{SO}_{4}\right)_{\mathrm{ad}}$ ion pairs with the $\mathrm{Pt}(111)$ surface seems to be strong enough to displace $\left(\mathrm{H}^{+}-\mathrm{SO}_{4}\right)_{\mathrm{ad}}$ from the electrode surface, as confirmed by the fact that the positive shift of the spike potential illustrated in Fig. 3 is accompanied by a clear decrease of the spike height (Fig. 2d), indicating a decrease of the domain size of the $(\sqrt{3} \times \sqrt{7}) R 19.1^{\circ}$ structure. However, the charge density in the potential region between the onset of bisulfate adsorption (just after the hydrogen adsorption region) and the double layer region remains roughly constant and independent of the $\mathrm{Cs}^{+}$concentration, suggesting that only the domain size of this structure is affected, the total amount of adsorbed sulfate species, $\left(\mathrm{H}^{+}-\mathrm{SO}_{4}\right)_{\mathrm{ad}}+\left(\mathrm{Cs}^{+}-\mathrm{SO}_{4}\right)_{\mathrm{ad}}$, remaining constant.

While neither $\mathrm{K}^{+}$nor $\mathrm{Cs}^{+}$changes the charge of (bi)sulfate adsorption below the hump, they slightly increase the charge of the hump, which is $c a .25 \mu \mathrm{C} \mathrm{cm}{ }^{-2}$ (without double layer correction) in cation-free solutions, also with $\mathrm{Li}^{+}$and $\mathrm{Na}^{+}$at the concentrations used in this work, and also with $\mathrm{K}^{+}$and $\mathrm{Cs}^{+}$ at $c_{\mathrm{M}^{+}} \leq 10^{-3} \mathrm{M}$. However, the charge increases to $28 \mu \mathrm{C} \mathrm{cm}^{-2}$ with $\mathrm{K}^{+}$and $\mathrm{Cs}^{+}$at $c_{\mathrm{M}^{+}}=10^{-2} \mathrm{M}$, to $30 \mu \mathrm{C} \mathrm{cm}^{-2}$ with $c_{\mathrm{K}^{+}}=$ $5 \times 10^{-2} \mathrm{M}$, and to $35 \mu \mathrm{C} \mathrm{cm}^{-2}$ with $c_{\mathrm{Cs}^{+}}=5 \times 10^{-2} \mathrm{M}$. Therefore, under these conditions, the total amount of adsorbed sulfate species $\left(\mathrm{H}^{+}-\mathrm{SO}_{4}(\mathrm{ad})+\mathrm{M}^{+}-\mathrm{SO}_{4}(\mathrm{ad})\right)$ is higher than in the absence (or at low enough concentrations) of cations. The additional amount of adsorbed sulfate species increases from $c a$. $0.03 \mathrm{ML}$ in the presence of $10^{-2} \mathrm{M} \mathrm{K}^{+}$or $\mathrm{Cs}^{+}$to $c a .0 .04 \mathrm{ML}$ in the presence of $5 \times 10^{-2} \mathrm{M} \mathrm{K}^{+}$and to $c a$. $0.05 \mathrm{ML}$ in the presence of $5 \times 10^{-2} \mathrm{M} \mathrm{Cs}^{+}$. These values agree reasonably well with the amount of $\mathrm{K}^{+}$estimated to adsorb in this potential region (ca. $0.03 \mathrm{ML}$ ) by Garcia-Araez et $a .^{7}$

This increase of the hump charge by the added cations renders difficult the derivation of an equation describing the behavior of the hump, because both the total adsorbate coverage and the composition of the adlayer at the hump are different in cationsfree and in cations-containing solutions, for different cations, and for the same cation at different concentrations. Nonetheless, it is evident from Fig. 3 that the shift of the hump potential with increasing cation concentration can be described by an equation similar to eqn (7), but with a positive sign for the $c_{\mathbf{M}^{+}}$term, since the cations now cooperate, instead of competing, with the phase transition, and therefore shift negatively the potential of the hump:

$$
E=E^{\prime}-\frac{R T}{n F} \ln \left(1+K_{\mathrm{M}}^{\text {hump }} c_{\mathrm{M}^{+}}\right)
$$

Although eqn (8) has not been derived using the same thermodynamic considerations as the other equations above, the negative shift of the hump potential can be intuitively understood. We have noted above that, in the absence of cations, the hump corresponds to a further increase of the bisulfate coverage by $0.025 \mathrm{ML}$, which disrupts the hydrogenbonded $(\sqrt{3} \times \sqrt{7}) R 19.1^{\circ}$ structure. The hump becomes more 
reversible, and its potential shifts negatively, at high enough concentrations of alkali-metal cations. In other words, in addition to helping to break the hydrogen bond network, which opposes further adsorption, the incorporation of cations increases the stability of the higher coverage and hydrogen bond-free adlayer formed in the hump.

An intriguing result is that, in the case of $\mathrm{Cs}^{+}$, a fit of the data to eqn (7) and (8) yields $n<2(n=0.2$ for the spike and $n=0.4$ for the hump; in the case of $\mathrm{K}^{+}$, and for the hump, $n=1$ ). In our previous work with cyanide-modified Pt(111) electrodes, ${ }^{9}$ this was attributed to the transfer through the interface of less than one electron per adsorbed pair, but this disagrees with the above analysis of the charge of the spike and the hump in the presence of $\mathrm{Cs}^{+}$. In the case of eqn (7), a more plausible explanation is that $n<2$ because of the decrease of $c_{\mathrm{SO}_{4}{ }^{2-}}$ with increasing $c_{\mathrm{M}^{+}}$, due to the formation of $\mathrm{MSO}_{4}{ }^{-}$pairs in the solution, which must provoke an additional positive shift of the spike potential. The use of the Langmuir isotherm, which is obviously an oversimplification, may also contribute to the observed deviation.

\section{Conclusions}

In summary, cations can adsorb on the electrode surface forming pairs with specifically adsorbing anions. These electrostatic (or, more generally speaking, non-covalent) interactions can affect the properties of the electrode-electrolyte interface, and therefore the processes that occur in this region, including, most importantly, electrocatalytic reactions. Our model is based on a simple description of the interaction between cations and specifically adsorbed anions, and fits very well the experimental data for two completely different adsorption processes, namely, the adsorption of hydrogen on cyanide-modified $\operatorname{Pt}(111)^{9}$ and the adsorption of (bi)sulfate on $\mathrm{Pt}(111)$ electrodes. The model provides quantitative data regarding the interaction between the cations and chemisorbed species, allowing us to understand trends as well as deviations from anticipated trends. ${ }^{9}$

In acidic media, the model must also include the competition between $\mathrm{M}^{+}$and $\mathrm{H}^{+}$for the interaction with surfaceanchored species, or, equivalently in the case treated in this contribution, the competition between $\left(\mathrm{H}^{+}-\mathrm{SO}_{4}\right)_{\mathrm{ad}}$ and $\left(\mathrm{M}^{+}-\mathrm{SO}_{4}\right)_{\mathrm{ad}}$ for the same metal sites. This competition results in a threshold cation concentration below which, in acidic media, cations have no measurable effect on interfacial processes. Due to the absence of competing $\mathrm{H}^{+}$in alkaline media, we do not expect such a threshold cation concentration to exist in this case. Rather, a continuous increase of the cation effect with increasing cation concentration is to be expected.

The recently reported effects of alkali-metal cations on several electrocatalytic reactions must be mediated by the interaction between these cations and chemisorbed species. Since these interactions seem to be adequately and quantitatively described by our model, we expect it to be useful to describe and explain those effects. In particular, taking into account the anticipated differences in the effect of cations in acidic and alkaline environments mentioned above, and the importance of $\mathrm{pH}$ in some relevant electrocatalytic reactions, ${ }^{40-42}$ our model could help to find optimal electrolyte compositions for electrocatalysis.

\section{Acknowledgements}

Funding from the DGI (Spanish Ministry of Education and Science) through Project CTQ2009-07017 is gratefully acknowledged. E.P.M.L. wishes to thank the Universidad Nacional de Córdoba, Argentina, for a grant within the "Programa de Movilidad Internacional de Profesores Cuarto Centenario".

\section{Notes and references}

1 V. E. Kazarinov and O. A. Petry, J. Electroanal. Chem., 1970, 27, A1-A2.

2 B. B. Damaskin, O. A. Petrii and V. E. Kazarinov, Elektrokhimiya, 1972, 8, 1373-1377.

3 N. García, V. Climent, J. M. Orts, J. M. Feliu and A. Aldaz, ChemPhysChem, 2004, 5, 1221-1227.

4 V. Climent, N. García-Araez and J. M. Feliu, Electrochem. Commun., 2006, 8, 1577-1582.

5 J. M. Feliu, M. J. Valls, A. Aldaz, M. A. Climent and J. Clavilier, J. Electroanal. Chem., 1993, 345, 475-481.

6 D. Strmcnik, K. Kodama, D. van der Vliet, J. Greeley, V. R. Stamenkovic and N. M. Marković, Nat. Chem., 2009, 1, 466-472.

7 N. Garcia-Araez, V. Climent, P. Rodriguez and J. M. Feliu, Phys. Chem. Chem. Phys., 2010, 12, 12146-12152.

8 D. F. van der Vliet and M. T. M. Koper, Surf. Sci., 2010, 604, 1912-1918.

9 M. Escudero-Escribano, M. E. Zoloff Michoff, E. P. M. Leiva, N. M. Marković, C. Gutiérrez and Á. Cuesta, ChemPhysChem, 2011, 12, 2230-2234.

10 M. Nakamura, N. Sato, N. Hoshi and O. Sakata, ChemPhysChem, 2011, 12, 1430-1434.

11 D. Strmcnik, D. F. van der Vliet, K. C. Chang, V. Komanicky, K. Kodama, H. You, V. R. Stamenkovic and N. M. Marković, J. Phys. Chem. Lett., 2011, 2, 2733-2736.

12 N. Danilovic, S. Ram, D. Strmcnik, A. P. Paulikas, D. Myers, V. R. Stamenkovic and N. M. Markovic, Electrocatalysis, 2012, 3, 221-229.

13 I. Katsounaros and K. J. J. Mayrhofer, Chem. Commun., 2012, 48, 6660-6662.

14 J. Suntivich, E. Perry, H. Gasteiger and Y. Shao-Horn, Electrocatalysis, 2013, 4, 49-55.

15 C. Stoffelsma, P. Rodriguez, G. Garcia, N. Garcia-Araez, D. Strmcnik, N. M. Marković and M. T. M. Koper, J. Am. Chem. Soc., 2010, 132, 16127-16133.

16 J. Clavilier, R. Faure, G. Guinet and R. Durand, J. Electroanal. Chem., 1980, 107, 205-209.

17 A. M. Funtikov, U. Stimming and R. Vogel, J. Electroanal. Chem., 1997, 428, 147-153.

18 O. M. Magnussen, J. Hageböck, J. Hotlos and R. J. Behm, Faraday Discuss., 1992, 94, 329-338. 
19 G. J. Edens, X. Gao and M. J. Weaver, J. Electroanal. Chem., 1994, 375, 357-366.

20 L.-J. Wan, S.-L. Yau and K. Itaya, J. Phys. Chem., 1995, 99, 9507-9513.

21 L.-J. Wan, M. Hara, J. Inukai and K. Itaya, J. Phys. Chem. B, 1999, 103, 6978-6983.

22 Y. G. Kim, J. B. Soriaga, G. Vigh and M. P. Soriaga, J. Colloid Interface Sci., 2000, 227, 505-509.

23 L.-J. Wan, T. Suzuki, K. Sashikata, J. Okada, J. Inukai and K. Itaya, J. Electroanal. Chem., 2000, 484, 189-193.

24 M. Wilms, P. Broekmann, C. Stuhlmann and K. Wandelt, Surf. Sci., 1998, 416, 121-140.

25 A. Kolics and A. Wieckowski, J. Phys. Chem. B, 2001, 105, 2588-2595.

26 K.-i. Ataka and M. Osawa, Langmuir, 1998, 14, 951-959.

27 A. Comas-Vives, J. Bandlow and T. Jacob, Phys. Chem. Chem. Phys., 2013, 15, 992-997.

28 A. Cuesta, M. Kleinert and D. M. Kolb, Phys. Chem. Chem. Phys., 2000, 2, 5684-5690.

29 P. W. Faguy, N. S. Marinković and R. R. Adžić, Langmuir, 1996, 12, 243-247.

30 R. Jinnouchi, T. Hatanaka, Y. Morimoto and M. Osawa, Phys. Chem. Chem. Phys., 2012, 14, 3208-3218.

31 O. M. Magnussen, Chem. Rev., 2002, 102, 679-726.
32 Y. Shingaya and M. Ito, J. Electroanal. Chem., 1999, 467, 299-306.

33 F. Simeone, D. Kolb, S. Venkatachalam and T. Jacob, Angew. Chem., Int. Ed., 2007, 46, 8903-8906.

34 F. C. Simeone, D. M. Kolb, S. Venkatachalam and T. Jacob, Surf. Sci., 2008, 602, 1401-1407.

35 S. Venkatachalam and T. Jacob, Z. Phys. Chem., 2007, 221, 1393-1406.

36 K.-Y. Yeh, N. A. Restaino, M. R. Esopi, J. K. Maranas and M. J. Janik, Catal. Today, 2013, 202, 20-35.

37 N. M. Marković, B. N. Grgur, C. A. Lucas and P. N. Ross, J. Phys. Chem. B, 1999, 103, 487-495.

38 C. Saravanan, M. T. M. Koper, N. M. Markovic, M. HeadGordon and P. N. Ross, Phys. Chem. Chem. Phys., 2002, 4, 2660-2666.

39 Y. Shingaya and M. Ito, Chem. Phys. Lett., 1996, 256, 438-444.

40 J. Joo, T. Uchida, A. Cuesta, M. T. M. Koper and M. Osawa, J. Am. Chem. Soc., 2013, 135, 9991-9994.

41 J. Joo, T. Uchida, A. Cuesta, M. T. M. Koper and M. Osawa, Electrochim. Acta, 2014, 129, 127-136.

42 S. Brimaud, J. Solla-Gullón, I. Weber, J. M. Feliu and R. J. Behm, ChemElectroChem, 2014, DOI: 10.1002/ celc. 201400011 . 